\title{
Gallium Ga 68-RGD
}

National Cancer Institute

\section{Source}

National Cancer Institute. Gallium Ga 68-RGD. NCI Thesaurus. Code C120104.

A radiopharmaceutical agent comprised of a cyclic arginine-glycine-aspartic acid (Arg-GlyAsp/RGD) peptide labeled with gallium Ga 68, with potential alphaVbeta3 integrin (avb3) imaging activity during positron emission topography (PET). After intravenous administration, gallium Ga 68-RGD selectively binds to avb3 on the cell membrane via the cyclic RGD motif. Upon PET imaging, avb3-expressing tumor cells can be visualized and their expression levels can be quantified. avb3, a member of the integ rin receptor family, is overexpressed on certain tumor cells and tumor endothelial cells while minimally or not expressed on healthy, normal cells; it plays a key role in angiogenesis, tumor proliferation and survival. 